\title{
The effect of propranolol and midazolam on the reconsolidation of a morphine place preference in chronically treated rats
}

\author{
Michael J. F. Robinson, Michael Armson and Keith B. J. Franklin* \\ Department of Psychology, Mc Gill University, Montreal, QC, Canada
}

Edited by:

Nuno Sousa, University of Minho,

Portugal

\section{Reviewed by:}

Nashaat Z. Gerges, Medical College of

Wisconsin, USA

José M. Pêgo, University of Minho,

Portugal

${ }^{*}$ Correspondence:

Keith B. J. Franklin, Department of

Psychology, McGill University, 1205 Dr.

Penfield Avenue, Montreal, QC,

Canada H3A 1 B1.

e-mail: keith.franklin@mcgill.ca
A stable memory can be disrupted if amnestic treatment is applied in conjunction with memory reactivation. Recent findings in the conditioned place preference (CPP) model suggest that blocking reconsolidation attenuates the ability of environmental cues to induce craving and relapse in drug addicts, but the impact of prior physical dependence has not been described. We examined the effect of post-reactivation amnestic treatment on reconsolidation of a CPP for morphine, in animals naïve to morphine, under chronic morphine experience or abstinent. Chronic morphine experience was induced by escalating doses of morphine from $10 \mathrm{mg} / \mathrm{kg} /$ day (s.c.), and maintained on $30 \mathrm{mg} / \mathrm{kg} /$ day during the course of conditioning and reactivation procedures, or conditioning alone. Naïve and morphine-experienced animals were trained in a three-compartment apparatus by four morphine ( $5 \mathrm{mg} / \mathrm{kg}$, s.c.) and four saline experiences paired with either of two large conditioning compartments. The memory was then reactivated by a CPP test, and immediately afterward animals received an injection of the beta-adrenergic antagonist propranolol (10 mg/kg, s.c.), the GABAa agonist midazolam (1 mg/kg, i.p.), or saline. Morphine-naïve rats received only a single reconsolidation-blocking treatment (Experiment 1), while chronic morphine rats were given eight reactivation sessions each followed by amnestic treatment, either before (Experiment 2) or after 10 days of withdrawal (Experiment 3). Propranolol and midazolam disrupted reconsolidation in morphine-naïve rats, but failed to disrupt the CPP when rats were trained under chronic morphine treatment, even if they were recovered from chronic opiate exposure before reactivation. In fact, propranolol increased the preference for the drug-paired context in animals trained while maintained on chronic morphine. Midazolam had little effect. Morphine experience may produce neurochemical changes which alter memory storage processes and reduce the impact of amnestic treatments on reconsolidation.

Keywords: reconsolidation, memory, reinforcement, place preference, morphine, midazolam, propranolol, drug dependence

\section{INTRODUCTION}

The treatment of drug addiction is characterized by a high incidence of relapse among recovered addicts, even after many years of abstinence (See, 2002). One reason for this is persistent drug craving which develops during the course of addiction as a result of associations between the rewarding effects of the drug and environmental cues (Eikelboom and Stewart, 1982; Childress et al., 1993; Frenois et al., 2005). Recently there has been interest in methods to attenuate cue-elicited craving and relapse (Tronson and Taylor, 2007). In animal tests, treatments such as propranolol, ketamine, or MK-801 disrupt memory reconsolidation for contextual cues previously associated with a rewarding drug such as morphine, amphetamine, or cocaine (Bernardi et al., 2006; Robinson and Franklin, 2007b; Sadler et al., 2007; Brown et al., 2008; Fricks-Gleason and Marshall, 2008; Zhai et al., 2008). These results suggest that reconsolidation-blocking procedures might have promise as a form of therapeutic treatment for preventing relapse in recovered addicts. However, one key element of addiction has not been explored in this context. Addiction typically occurs after prolonged drug use that leads to neural changes associated with dependence and tolerance (Lukacher et al., 1987;
Volkow et al., 1988; Terwilliger et al., 1991; Stimmel and Kreek, 2000; Kreek, 2001; Kosten and George, 2002). Opiates are said to deregulate the noradrenergic system and second messenger pathways such as adenylyl cyclase (AC) and cyclic AMP (cAMP; Nestler, 1993; Gintzler and Chakrabarti, 2006). The central noradrenergic system, especially the locus ceruleus, is rendered hypoactive as a result of dependence, and becomes hyperactive during opiate withdrawal (Aghajanian, 1978; Akaoka and AstonJones, 1991). In addition chronic reduction of noradrenaline release up-regulates both beta- 1 and alpha- 1 receptors and causes functional supersensitivity to noradrenaline (Kuriyama et al., 1981a,b; Mogilnicka, 1986). Stimulation of the beta-adrenergic receptor also leads to activation of AC and cAMP which have a direct impact on gene transcription and regulation of memory processes (Tronson and Taylor, 2007). Beta-receptors promote consolidation, reconsolidation, and retrieval while alpha receptors modulate this effect (Kuriyama et al., 1981b; Ferry et al., 1999; Sirvio and MacDonald, 1999; Kobayashi and Yasoshima, 2001; Sara, 2009; Gibbs et al., 2010) in various ways. In animals that have never been drug dependent, blocking this pathway with the beta-adrenergic antagonist propranolol disrupts reconsolidation 
for a place preference conditioned by morphine (Robinson and Franklin, 2007b) or cocaine (Bernardi et al., 2006), but the impact of chronic morphine on the effect of propranolol in reconsolidation is not known. Since propranolol's memory blocking effects presumably depend on its interference with noradrenergic memory mechanisms, the question arises as to whether the effects of chronic exposure to morphine on the noradrenergic system, alter the effect of propranolol as a reconsolidation-blocking agent.

Chronic morphine exposure alters the expression of a variety of receptors including GABAa receptors (Ammon-Treiber and Hollt, 2005). Benzodiazepines such as midazolam, which act as a GABAa agonist, suppress signs of morphine withdrawal in both rats and mice, and it has been suggested they can decrease morphine tolerance and dependence in the rat by interacting with the opioidergic system (Rattan and Tejwani, 1997; Cao et al., 2002). Like propranolol, midazolam disrupts memory reconsolidation of conditioned fear (Bustos et al., 2006, 2009; Zhang and Cranney, 2008), and of a morphine conditioned place preference (CPP; Robinson and Franklin, 2010), but it has been tested only in non-dependent rats. Currently the impact of GABAa receptor modifications induced by chronic morphine on the effects of midazolam in reconsolidation is not known.

We have therefore examined the effect of propranolol and midazolam on the reconsolidation of a morphine-CPP in rats with (1) no prior chronic morphine experience, (2) rats maintained on high doses of chronic morphine during both conditioning and reactivation, and (3) in animals where reactivation occurred after 10 days of withdrawal from previous chronic morphine experience. Since chronic morphine experience occurring at the time of morphine place conditioning might strengthen the CPP and render it harder to disrupt, we hypothesized that repeated reconsolidation-blocking treatments may potentiate the amnestic effects (Sadler et al., 2007; Fricks-Gleason and Marshall, 2008; Robinson and Franklin, 2010). Therefore animals with a history of chronic morphine treatment were subjected to eight reconsolidation-blocking sessions. Propranolol was used in a dose of $10 \mathrm{mg} / \mathrm{kg}$ because this dose has been shown to block the increase in excitability of hippocampal neurons induced by noradrenaline (Kitchigina et al., 1997) and to disrupt memory reconsolidation in appetitive and fear paradigms (Przybyslawski et al., 1999; Robinson and Franklin, 2007b, 2010; Lee and Everitt, 2008). Midazolam was used in a dose of $1 \mathrm{mg} / \mathrm{kg}$ because this dose blocks reconsolidation (Bustos et al., 2006; Robinson and Franklin, 2010) but does not produce strong sedation in young rats (Bessa et al., 2005).

\section{MATERIALS AND METHODS ANIMALS}

Subjects were male Long Evans rats (125-150 g) from Charles River, St Constant, QC, Canada. They were weighed and handled daily beginning 3-5 days prior to the start of place conditioning. Rats were individually housed in a colony room, maintained on a 12-h light-dark cycle (lights on at $7 \mathrm{am}$ ) with a constant temperature of approximately $21^{\circ} \mathrm{C}$, and had food and water available ad libitum. This research was reviewed by the Animal Ethics Committee of McGill University and carried out in accordance with the guidelines of the Canadian Council on Animal Care.

\section{APPARATUS}

The CPP apparatus consisted of three compartments, as previously described (Robinson and Franklin, 2007b). Compartments A and $B$ were identical in size $(36 \mathrm{~cm} \times 34 \mathrm{~cm} \times 26 \mathrm{~cm})$, but differed in floor and ceiling color (black vs white), the orientation of the stripes on the wall (vertical vs horizontal), and by the diameter of the wire mesh flooring $(1.2 \mathrm{vs} 0.6 \mathrm{~cm})$. They were located side by side and had shaded plexiglass front walls. Compartment $\mathrm{C}$ $(20 \mathrm{~cm} \times 14 \mathrm{~cm} \times 28 \mathrm{~cm})$ was attached to the rear of compartments $\mathrm{A}$ and $\mathrm{B}$ and connected them via guillotine doors in the rear wall of compartments A and B. When the doors were lowered, the rat was confined to one of the larger compartments. When the doors were removed, the rat could move freely between compartments $\mathrm{A}$ and $B$ via compartment $C$. Position sensors in each compartment were connected to a computer which calculated the location of the animal at all times.

\section{PLACE CONDITIONING PROCEDURE}

On the first day of training animals were introduced via box $\mathrm{C}$ and allowed to explore freely all three boxes for $30 \mathrm{~min}$. Time spent in each compartment was recorded, and was used to verify that the rats did not exhibit any spontaneous preference for a given compartment.

On each conditioning day the rat was brought to the test room, injected (s.c.) with the drug (or vehicle), and immediately confined to compartment A or B for $30 \mathrm{~min}$. On alternate days, the rat was injected with the vehicle (or drug), and confined for $30 \mathrm{~min}$ to the other compartment. The order of injection (drug or vehicle) and the compartment paired with the drug (A or B) was counterbalanced within each group. On test days each rat was introduced via the alley box (box C) and allowed to move freely in all three boxes for $30 \mathrm{~min}$. Time spent in each compartment was recorded.

\section{CHRONIC MORPHINE TREATMENT: INDUCTION AND MAINTENANCE}

Rats received single daily injections of morphine (s.c.) around $6 \mathrm{pm}$ each day, starting 5 days before CPP training. They received $10 \mathrm{mg} /$ $\mathrm{kg}$ on day 1 and the dose was increased by $5 \mathrm{mg} / \mathrm{kg}$ each day up to $30 \mathrm{mg} / \mathrm{kg}$ the day before training began. Rats were subsequently maintained on daily injections of $30 \mathrm{mg} / \mathrm{kg}$ until withdrawal was induced by cessation of the treatment. Previous studies have shown that either a single injection of morphine $(30 \mathrm{mg} / \mathrm{kg}$, s.c.) or daily injections $(10 \mathrm{mg} / \mathrm{kg}$, s.c.) over a period of 14 days, produces behavioral sensitization and neuroadaptations that last up to 3 weeks (Vanderschuren et al., 1997, 2001), and doses as low as $10 \mathrm{mg} / \mathrm{kg}$ for 5 days induce dependence as indicated by naloxone-precipitated withdrawal signs (Frumkin, 1974; Mucha et al., 1979).

After their last dose of morphine rats were withdrawn for 10 days. According to several studies, most of the symptoms of withdrawal have disappeared after 10 days of abstinence (Cox and Valenstein, 1969; Khavari et al., 1975; Stinus et al., 1998; Gekht et al., 2003).

\section{EXPERIMENT 1: THE EFFECT OF PROPRANOLOL AND MIDAZOLAM ON RECONSOLIDATION IN MORPHINE-NAIVE RATS}

Morphine-naïve rats were pre-exposed to the apparatus on the first day and then conditioned with four drug (morphine $5 \mathrm{mg} / \mathrm{kg}$, s.c.) pairings and four vehicle pairings over eight consecutive days. The day following conditioning, rats received a 30-min test which also 
acted as a reactivation session. Immediately after reactivation rats received an injection of propranolol (10 mg/kg, s.c.), midazolam ( $1 \mathrm{mg} / \mathrm{kg}$, i.p.), or vehicle. Animals were tested 2 and 7 days after reactivation to see if the memory for the CPP persisted. The design of this experiment and Experiment $2 \mathrm{a}$ and $\mathrm{b}$ are summarized in Figure 1.

\section{EXPERIMENT 2A: THE EFFECT OF PROPRANOLOL AND MIDAZOLAM ON RECONSOLIDATION IN ANIMALS MAINTAINED ON CHRONIC MORPHINE TREATMENT DURING CONDITIONING AND REACTIVATION}

The second experiment differs from the first in that rats were submitted to a chronic morphine regimen (30 mg/kg/day, s.c.) prior to training, and maintained under this regimen throughout conditioning and reactivation. Conditioning was the same as Experiment 1. In order to reduce the possibility of overdose, animals were conditioned around midday each day with morphine ( $5 \mathrm{mg} / \mathrm{kg}$, s.c.) or saline, and received their chronic morphine maintenance dose around $6 \mathrm{pm}$.

The reactivation sessions began $48 \mathrm{~h}$ after the last conditioning session and were repeated eight times, at $24 \mathrm{~h}$ intervals. Each reactivation session doubled as a test of the previous treatment. Immediately after each reactivation session, animals were injected with either propranolol (s.c.), midazolam (i.p.), or vehicle. Following the eighth reactivation session, morphine maintenance was discontinued and animals were re-tested drug free after 10 days.

\section{EXPERIMENT 2B: THE EFFECT OF A PERIPHERAL BETA-BLOCKER ON RECONSOLIDATION IN ANIMALS MAINTAINED ON CHRONIC MORPHINE TREATMENT DURING CONDITIONING AND REACTIVATION}

This experiment assessed the effect of peripheral beta-blockade on reconsolidation in chronically morphine treated animals. A single group of animals was induced and maintained on a chronic morphine regimen $(30 \mathrm{mg} / \mathrm{kg} /$ day, s.c.) leading up to, and for the duration of, conditioning and reactivation sessions, in the same manner as in Experiment 2a. However in this case animals received injections of the peripheral beta-blocker nadolol (10 mg/kg, s.c.) after each reactivation session.

\section{EXPERIMENT 3: RECONSOLIDATION IN ANIMALS MAINTAINED ON CHRONIC MORPHINE TREATMENT DURING CONDITIONING, BUT NOT REACTIVATION.}

The aim of this experiment was to assess whether the effects of chronic morphine treatment on reconsolidation were long lasting, and would persist if reactivation occurred following discontinuation of chronic morphine treatment. This experiment followed the same protocol as Experiment 2 with regards to the induction and maintenance of chronic morphine treatment $(30 \mathrm{mg} / \mathrm{kg} / \mathrm{day}$, s.c.) and conditioning. However, rats received their last chronic morphine injection on the final day of conditioning. Morphine maintenance was discontinued for 10 days before the reactivation protocol began. As in Experiment 2, animals were reactivated once a day for eight consecutive days, and injected with either propranolol (s.c.), midazolam (i.p.), or vehicle immediately after each session.

\section{EXPERIMENT 4: THE EFFECT OF POST-TRIAL PROPRANOLOL INJECTIONS IN MORPHINE MAINTAINED AND MORPHINE-NAIVE ANIMALS}

The aim of this experiment was twofold. First it examined whether a single post-session propranolol injection could induce a change in preference for the compartment with which it was explicitly paired. In other words, can a single injection of propranolol that is predicted by exposure to an environment impart motivational properties to that environment, which could interact with motivational

\begin{tabular}{|c|c|c|c|c|c|c|c|}
\hline & Pre-exposure & Conditioning & \multicolumn{5}{|c|}{ Reactivation/Test } \\
\hline Expt 1 & $\begin{array}{l}1 \text { free } \\
\text { exploration } \\
\text { trial }\end{array}$ & $\begin{array}{l}4 \text { morphine and } \\
4 \text { saline } \\
\text { conditioning } \\
\text { trials }\end{array}$ & $\begin{array}{l}\text { Reactivatio } \\
\text { followed } \\
\text { by amnesti } \\
\text { drug }\end{array}$ & 1 day & 1 Test & st 5 days & ys 1 Test \\
\hline Expt 2a \& 2b & $\begin{array}{l}1 \text { free } \\
\text { exploration } \\
\text { trial }\end{array}$ & $\begin{array}{l}4 \text { morphine and } \\
4 \text { saline } \\
\text { conditioning } \\
\text { trials }\end{array}$ & \multicolumn{3}{|c|}{$\begin{array}{l}8 \text { reactivations } \\
\text { followed by amnestic } \\
\text { drug }\end{array}$} & $\begin{array}{l}10 \\
\text { days }\end{array}$ & 1 Test \\
\hline $\begin{array}{l}\text { Daily morphine } \\
10->30 \mathrm{mg} / \mathrm{kg}\end{array}$ & \multicolumn{2}{|c|}{ Daily morphine $(30 \mathrm{mg} / \mathrm{kg}$} & \multicolumn{5}{|c|}{$\begin{array}{l}\text { Forced } \\
\text { abstinence }\end{array}$} \\
\hline Expt 3 & $\begin{array}{l}1 \text { free } \\
\text { exploration } \\
\text { trial }\end{array}$ & $\begin{array}{l}4 \text { morphine and } \\
4 \text { saline } \\
\text { conditioning } \\
\text { trials }\end{array}$ & 10 days & \multicolumn{4}{|c|}{$\begin{array}{l}8 \text { reactivations } \\
\text { followed by amnestic } \\
\text { drug }\end{array}$} \\
\hline $\begin{array}{l}\text { Daily morphine } \\
10->30 \mathrm{mg} / \mathrm{kg}\end{array}$ & \multicolumn{2}{|c|}{$\begin{array}{l}\text { Daily morphine }(30 \mathrm{mg} / \mathrm{kg}) \\
\text { maintenance }\end{array}$} & \multicolumn{5}{|c|}{$\begin{array}{l}\text { Forced } \\
\text { abstinence }\end{array}$} \\
\hline
\end{tabular}

FIGURE 1 | Schematic diagram of the sequence of events and procedures in Experiments 1, 2a, 2b, and 3. Amnestic drugs are propranolol, midazolam, nadolol, or saline, depending on the experiment. Dark and light shaded areas below an experiment represent the escalation and maintenance of chronic morphine treatment and the transition to forced abstinence. Vertical dashed lines divide the different phases of each experiment. 
properties imparted by CPP conditioning. Second, it examined whether repeated pairings, in this case four, of post-session injections of propranolol with a compartment could impart motivational properties to that environment. Prior to any behavioral procedures one group of rats was maintained on chronic morphine treatment as previously described, while another group received repeated saline injections. Following an initial pre-exposure session, animals were confined to one compartment for $30 \mathrm{~min}$ and received a propranolol (10 $\mathrm{mg} / \mathrm{kg}$, s.c.) injection upon exiting the compartment designated as CS+. Animals received a saline injection on the alternate day following a 30-min exposure to the other compartment. Twenty-four hours later, all animals were allowed to run freely between compartments and their time in each compartment was recorded, to assess whether a place preference or aversion had developed. The 2-day cycle of conditioning was repeated three more times over the next 6 days for a cumulated total of four propranolol and four saline pairings. The next day both groups of rats were tested with a free choice of compartment.

\section{DRUGS AND INJECTIONS}

For conditioning, morphine sulfate (Sabex, QC, Canada) was diluted to $5 \mathrm{mg} / \mathrm{ml}$ in $0.9 \%$ sodium chloride (saline), and given (s.c.) at a dose of $1 \mathrm{ml} / \mathrm{kg}$. Saline was used for control injections in the same volume. For induction and maintenance of chronic morphine treatment, morphine sulfate was diluted to 10 and $30 \mathrm{mg} /$ $\mathrm{ml}$ in $0.9 \%$ sodium chloride (saline).

Propranolol hydrochloride and nadolol (Sigma-Aldrich, USA, Ltd.) were dissolved in $0.9 \%$ sodium chloride to a concentration of $10 \mathrm{mg} / \mathrm{ml}$ and given subcutaneously. Midazolam (Sandoz, Canada, Inc.) was provided in vials of $5 \mathrm{mg} / 5 \mathrm{ml}$ and injected (i.p.) at a dose of $1 \mathrm{mg} / \mathrm{kg}$. We have previously found that there is no effect of the route of injection of saline (Robinson and Franklin, 2010) so controls received an equivalent volumes of saline subcutaneously.

\section{STATISTICAL ANALYSIS}

Data collected during pre-exposure and test/reactivation sessions consisted of time spent in seconds in each of the three chambers in the apparatus. Animals which did not display a preference (drug time - saline time $>0$ ) for the drug-paired compartment on the first reactivation were excluded from analysis [Experiment 1 ( 1 out of 31 ); Experiment $2 \mathrm{a}$ ( 0 out of 38 ), $2 \mathrm{~b}$ ( 0 out of 13 ); Experiment 3 (4 out of 40); Experiment 4 (Propranolol conditioning - no animals excluded)].

The experimental hypotheses were that morphine produces a $\mathrm{CPP}$, amnestics attenuate the memory for the CPP, and that this effect is stable over time. These hypotheses are most powerfully tested by within group comparisons. The hypotheses specify which group differences are meaningful and the direction of effects. We therefore used ANOVA with planned contrasts to maximize power. We first examined whether each group showed a significant preference for the drug-paired over the vehicle-paired compartment on each trial. The ANOVA (Statistica) was with one repeated measure (the time each animal spent in either compartment). In this design only a subset of the possible between-cell comparisons is meaningful so we used a priori contrasts to increase power and reduce the risk of Type II errors. Since morphine is known to produce a CPP it was predicted that all groups would prefer the morphine-paired side, thus significance tests for the CPP were onetailed (alpha $=0.05)$. In Experiment 4 the effect of propranolol was unknown so two-tailed Tests were used. Note that this strategy is conservative because incorrectly accepting the null hypothesis for the CPP would increase the probability of reporting a reconsolidation block where none was present.

We also determined whether there were significant shifts in preference within treatment groups from the initial preference on the first reactivation to each subsequent reactivation (Experiments 1, $2 \mathrm{a}$, and 3). The ANOVA (Statistica) was with one repeated measure, comparing the preference score (time spent in drug compartment - time in saline compartment) on the initial reactivation day against the preference score on each subsequent test/reactivation day (two-tailed).

For Experiment 2b, $t$-tests were used to confirm a preference for the morphine context (time spent in morphine vs saline-paired compartment), and to compare the preference score (time spent in morphine - saline-paired compartment) on the initial reactivation to the preference score on each subsequent reactivation.

An ANOVA comparing the time spent in the left vs the right compartment for each group was run on the pre-exposure session for each experiment to confirm the apparatus was unbiased. The pre-exposure scores were not used in the calculation of the size of the CPP.

To assess the effect of propranolol as a reconsolidation treatment on a morphine-induced CPP across varying levels of chronic morphine experience (Experiments 1,2a, and 3), the preference score on the initial reactivation day for the three propranolol-treated groups was compared to the preference expressed on the following test day.

\section{RESULTS \\ EXPERIMENT 1: THE EFFECT OF PROPRANOLOL AND MIDAZOLAM ON RECONSOLIDATION IN MORPHINE-NAIVE RATS}

During pre-exposure to the apparatus none of the groups displayed a significant preference for either compartment $[F(2,27)=0.194$, NS], confirming the apparatus was unbiased.

After four cycles of conditioning, all three groups displayed a significant preference for the drug-paired compartment [Reactivation: Propranolol: $F(1,27)=38.314, p<0.001$; Midazolam: $F(1,27)=30.187, p<0.001$; Saline: $F(1,27)=20.615, p<0.001]$. There was no difference in preference between these three groups $[F(2,27)=0.499$, NS; Figure 2].

Two days later, animals were tested (Test 1 ) to assess the effect of the previous amnestic treatment on the morphine place preference. As can be seen in Figure 2, the group administered saline following initial reactivation still displayed a significant place preference [Saline: $F(1,27)=6.395, p<0.001]$. However, the groups injected post-reactivation with propranolol or midazolam no longer displayed a preference for the drug-paired compartment [Propranolol: $F(1,27)=1.374$, NS; Midazolam: $F(1,27)=2.103$, NS]. For the propranolol-treated group the decline in preference from the reactivation session was significant $[F(1,27)=5.013, p<0.025]$.

When animals were re-tested 7 days after initial the reactivation, the saline group again displayed a preference for the drug-paired compartment [Saline: $F(1,27)=5.919, p<0.01$ ], whereas the propranolol and midazolam treated groups did not [Propranolol: $F(1,27)=1.435$, NS; Midazolam: $F(1,27)=1.041$, NS]. In addition, for the groups 
treated with propranolol and midazolam the CPP was reduced relative to the initial reactivation [Reactivation to Test 2: Propranolol: $F(1,27)=5.265, p<0.05$; Midazolam: $F(1,27)=4.283, p<0.05]$.

\section{EXPERIMENT 2A: THE EFFECT OF PROPRANOLOL AND MIDAZOLAM ON RECONSOLIDATION IN ANIMALS MAINTAINED ON CHRONIC MORPHINE TREATMENT DURING CONDITIONING AND REACTIVATION}

There was no preference for either compartment prior to conditioning $[F(2,35)=1.888$, NS $]$.

Upon initial reactivation, following four morphine/saline conditioning pairings, all three groups displayed a significant preference for the drug-paired compartment [Reactivation 1: Propranolol: $F(1,35)=44.585, p<0.001$; Midazolam: $F(1,35)=62.273, p<0.001$; Saline: $F(1,35)=55.057, p<0.001$ ] , and there was no significant difference in preference between the three groups [ANOVA, $F(2,35)=0.921$, NS; Figure 3 ]. Immediately after this first reactivation session, animals were injected with propranolol, midazolam, or saline, and this procedure was repeated every $24 \mathrm{~h}$ for the next 7 days, for a total of eight reactivation sessions. During the course of these reactivation/test sessions (Figure 3), the animals treated with saline displayed a consistent preference for the drug-paired compartment [Reactivation 1-8: Fs $(1,35)>6.293, p<0.01$ ]. Similarly, the animals given midazolam after each reactivation session continued to show a CPP [Reactivation $1-8$ : Fs $(1,35)>5.889, p<0.01$ ], as did the group receiving propranolol following each reactivation [Reactivation 1-8: Fs $(1,35)>3.696, p<0.05]$. For the midazolam and saline treated groups, the size of the preference did not change.

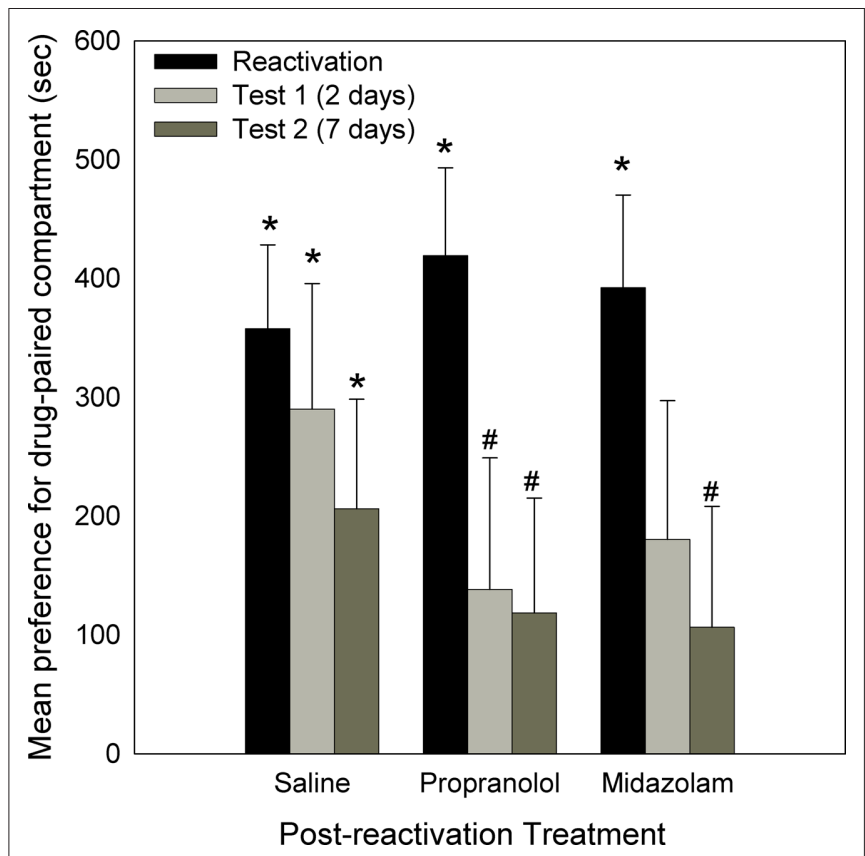

FIGURE 2 | Effect of Propranolol ( $10 \mathrm{mg} / \mathrm{kg} ; N=10$ ), Midazolam (1 mg/kg; $N=9)$, or Saline $(N=11)$ given post-reactivation, on the expression of a morphine-induced place preference (Experiment 1). Data are the mean time spent in the morphine-paired compartment minus time in the vehicle-paired compartment on reactivation, or tests 2 or 7 days postreactivation. Error bars $=$ SEM. ${ }^{*}=p<0.05$ for morphine vs vehicle-paired; $\#=p<0.05$ for reactivation vs test.
However, propranolol treatment increased the preference for the compartment previously associated with morphine [Reactivation 1 to Reactivation 2-4: Fs $(1,35)>5.510, p<0.025$ ].

Reactivation 8 (Test 7) marked the end of reconsolidation treatments and the last day of chronic morphine maintenance. Following 10 days of forced abstinence all three groups displayed a significant place preference [Test 8: Propranolol: $F(1,35)=4.406, p<0.025$; Midazolam: $F(1,35)=3.795, p<0.05$; Saline: $F(1,35)=3.165$, $p<0.05$; Figure 4]. However, for both the saline and midazolam treated animals the preference was decreased from their initial preference [Reactivation 1 to Test 8: Midazolam: $F(1,35)=5.809$, $p<0.025$; Saline: $F(1,35)=5.337, p<0.05]$.

\section{EXPERIMENT 2B: THE EFFECT OF A PERIPHERAL BETA-BLOCKER ON RECONSOLIDATION FOR ANIMALS MAINTAINED ON CHRONIC MORPHINE TREATMENT DURING CONDITIONING AND REACTIVATION}

As can be seen in Figure 4, these animals displayed a significant preference for the drug-paired compartment on the initial reactivation $[F(1,12)=48.03, p<0.001]$. The preference remained

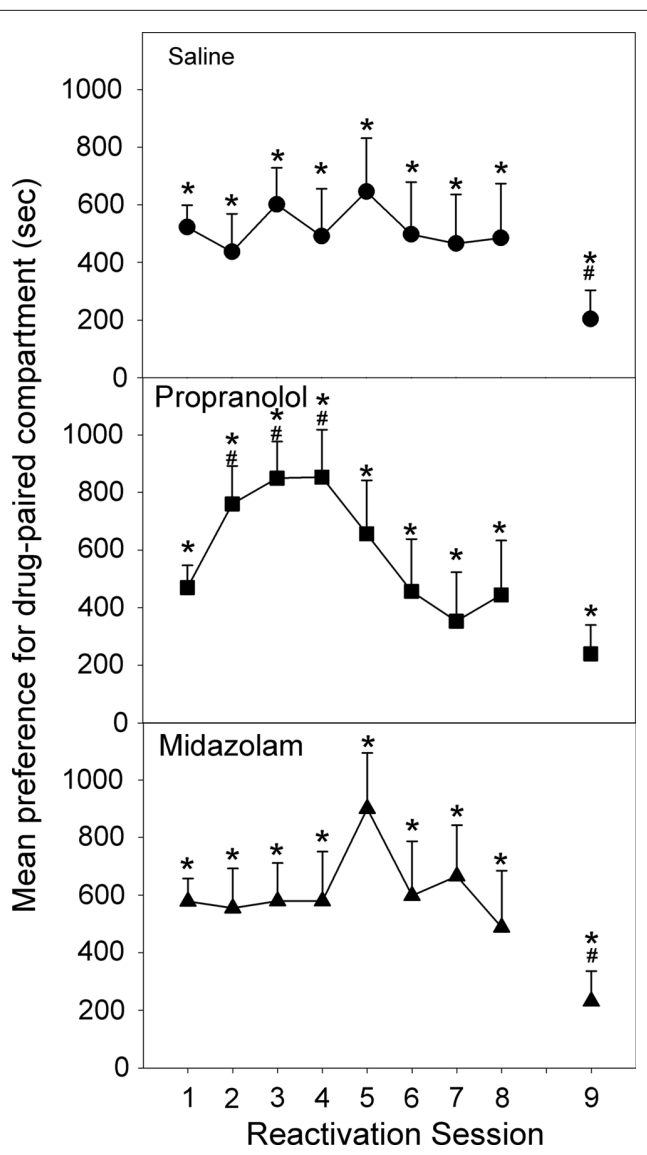

FIGURE 3 | Effect of Propranolol (10 mg/kg; $N=13$ ), Midazolam (1 mg/kg; $N=12)$, or Saline ( $N=13$ ) given post-reactivation on the expression of a morphine-induced place preference, in animals conditioned and reactivated under chronic morphine treatment (Experiment 2a). Data are the mean time spent in the morphine-paired compartment minus time in the vehicle-paired compartment on reactivations 1-8, or when tested after 10 days of withdrawal (Test 9). Error bars $=$ SEM. ${ }^{*}=p<0.05$ for morphine vs vehicle-paired; $\#=p<0.05$ for difference from reactivation 1 . 
significant throughout the reactivation sessions $[F \mathrm{~s}(1,12)>4.12$, $p<0.05]$. Rats given nadolol post-reactivation did not shift their preference from their initial reactivation on any of the seven following reactivation sessions $[F(1,12)<0.77, \mathrm{NS}]$. Following 10 days of withdrawal, the nadolol-treated animals still displayed a significant preference for the drug-paired compartment $[F(1,12)=6.55, p<0.01]$ but the CPP was smaller than on the initial test $[F(1,12)=16.42, p<0.05]$.

\section{EXPERIMENT 3: RECONSOLIDATION IN ANIMALS MAINTAINED ON CHRONIC MORPHINE TREATMENT DURING CONDITIONING, BUT NOT REACTIVATION}

The pre-exposure revealed no initial bias for either compartment $[F(2,33)=0.727, \mathrm{NS}]$.

Following four cycles of conditioning under chronic morphine treatment, morphine maintenance injections were stopped and animals were allowed to recover over the course of 10 days before beginning the reactivation phase. On the initial reactivation, all three groups displayed a significant preference for the drug-paired compartment [Reactivation 1: Propranolol: $F(1,33)=38.792$, $p<0.001$; Midazolam: $F(1,33)=26.561, p<0.001$; Saline: $F(1,33)=37.189, p<0.001]$, and there was no significant difference in preference between the groups [ANOVA, $F(2,33)=0.171$, NS; Figure 5]. Twenty-four hours after post-reactivation treatment with saline, the controls retained a significant place preference which persisted for six reactivation sessions [Reactivation 1-6: Saline: Fs $(1,33)>5.135, p<0.05]$ but faded on reactivation 7 and 8 [Saline: Fs $(1,33)<0.991$, NS]. For the last two reactivation sessions the preference decreased significantly from the preference on reactivation 1 [Reactivation 1 to Reactivation 7/8: Saline: Fs $(1,33)>4.949, p<0.05]$.

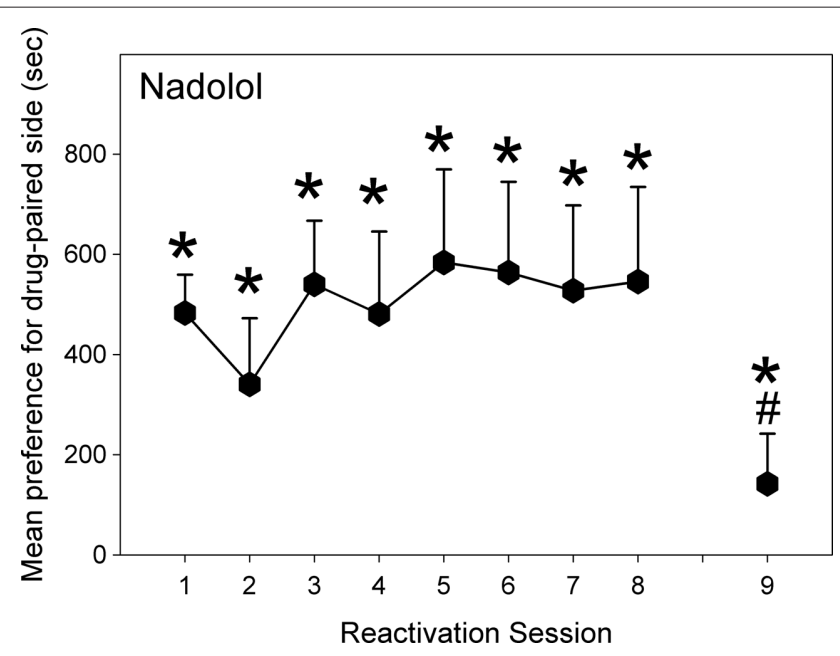

FIGURE 4 | Effect of Nadolol ( $10 \mathrm{mg} / \mathrm{kg} ; N=13$ ) given post-reactivation on the expression of a morphine-induced place preference, in animals conditioned and reactivated under chronic morphine treatment (Experiment 2b). Data are the mean time spent in the morphine-paired compartment minus time in the vehicle-paired compartment on reactivations $1-8$, or when tested after 10 days of withdrawal (Test 9). Error bars = SEM

* $=p<0.05$ for morphine vs vehicle-paired; $\#=p<0.05$ for difference from reactivation 1 .
The group receiving post-reactivation propranolol showed a preference for the drug-paired compartment on all eight reactivation sessions [Reactivation 1-8: Propranolol: Fs $(1,33)>6.124$, $p<0.015]$. Furthermore, the size of the drug-side preference increased between the first and fifth reactivation, after four postreactivation propranolol treatments [Reactivation 1 to Reactivation 5: Propranolol: $F(1,33)=10.225, p<0.001]$. The group treated with midazolam following each reactivation session displayed a significant preference for the drug-paired compartment on all but the sixth reactivation session [Reactivation 6: $F(1,33)=2.715$, NS; Reactivation 1-8: Fs $(1,33)>2.950, p<0.05$ ].

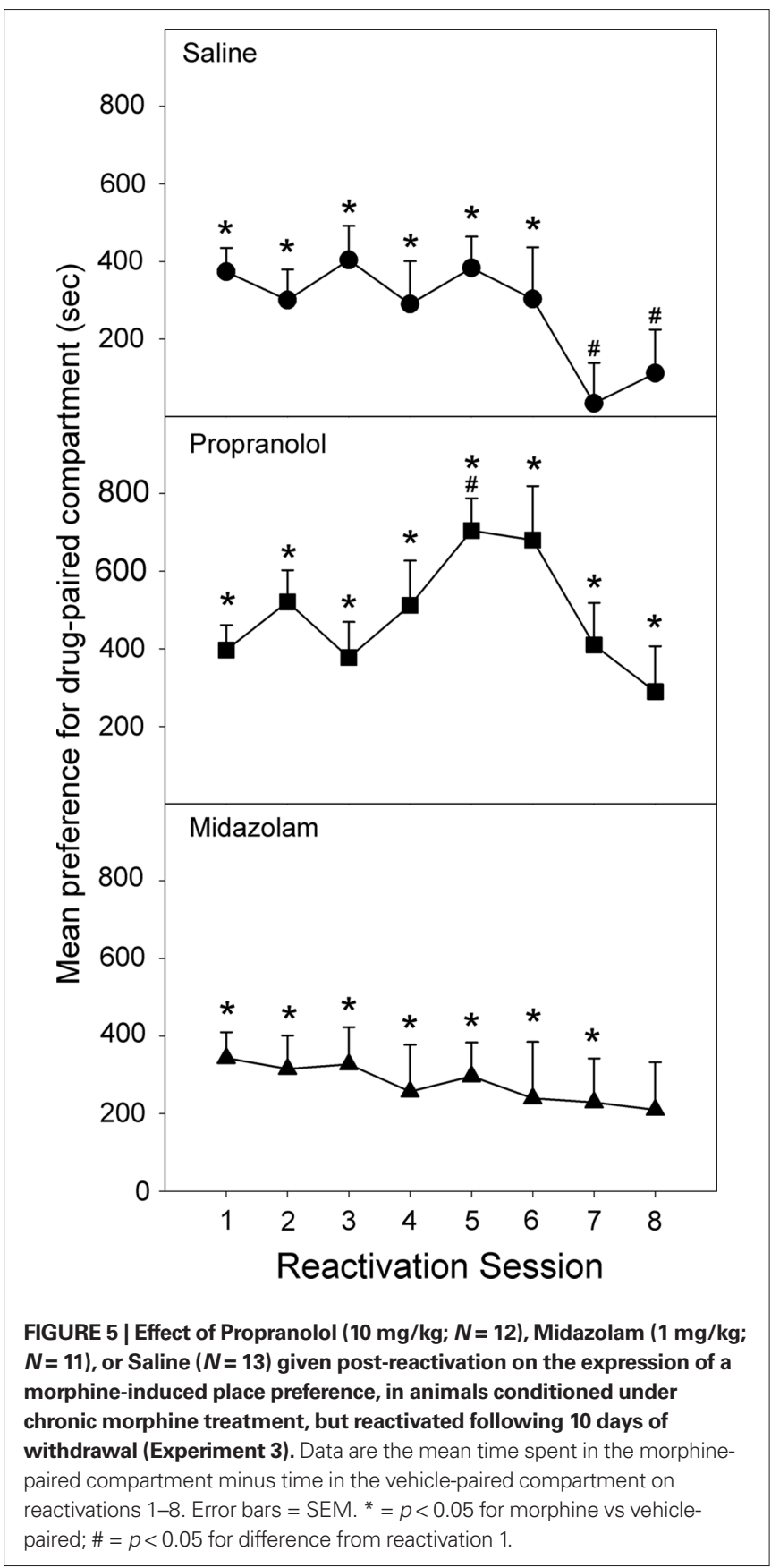




\section{THE IMPACT OF CHRONIC MORPHINE EXPERIENCE ON PROPRANOLOL'S EFFECT ON RECONSOLIDATION}

Figure 6 shows the impact of chronic morphine experience on the effect of propranolol as a reconsolidation-blocking treatment given after the initial reactivation. As can be seen, there was an interaction between chronic morphine treatment and the reactivation trial $[F(2,32)=8.304, p<0.01]$. When the trials were considered separately, there were no differences between the groups on trial 1 before propranolol treatment $[F(2,32)=0.275$; NS]. However, after reconsolidation (reactivation 2 ) an effect of chronic morphine treatment was apparent $[F(2,32)=8.225, p<0.01]$. Chronically treated (Experiment 2a) subjects had a significantly larger preference than naïve subjects (Experiment 1; Tukey HSD, $p<0.05$ ). Animals with a history of chronic morphine treatment but that were reactivated following withdrawal (Experiment 3 ) had a marginally larger CPP than naïve subjects (Tukey HSD, $p=0.051$ ) but did not differ from chronically treated subjects (Experiment 2a).

\section{EXPERIMENT 4: THE EFFECT OF POST-TRIAL PROPRANOLOL INJECTIONS IN MORPHINE MAINTAINED AND MORPHINE-NAIVE ANIMALS}

The pre-exposure revealed no initial bias for either compartment $[F(1,19)=0.164, \mathrm{NS}]$.

Following a single pairing with propranolol neither chronically treated or naive animals showed a preference for one compartment, as can be seen in Figure 7 [Test 1: Chronic morphine: $F(1,19)=0.419$, NS; Naive: $F(1,19)=0.146$, NS]. However, when animals were tested after four conditioning cycles, both groups displayed a significant place aversion for the propranolol-paired compartment [Test 2: Chronic morphine: $F(1,19)=18.230, p<0.001$; Naive: $F(1,19)=4.737$, $p<0.05]$. There was no significant difference in the size of the aversion between groups on Test 2 [ANOVA: $F(1,19)=2.523$, NS] .

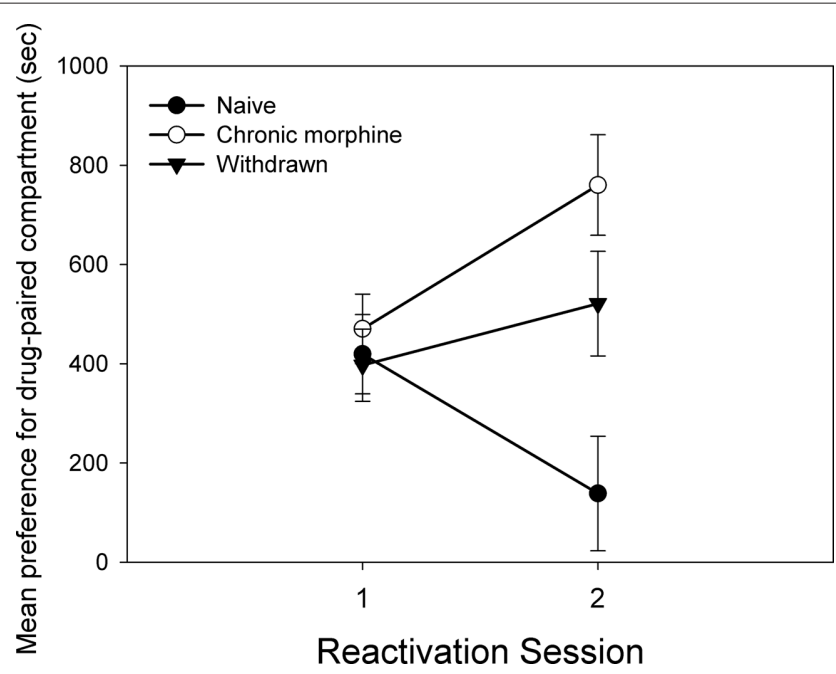

FIGURE 6 |The figure compares the preference for the morphine-paired context of the propranolol-treated groups on the initial reactivation and the subsequent reconsolidation test, for different degrees of experience with morphine (Experiment 1: Naive; Experiment 2a: Chronic morphine; Experiment 3:Withdrawn). Data is the mean time spent in the morphinepaired compartment minus time in the vehicle-paired compartment on the initial reactivation and the following test day. Error bars $=$ SEM.

\section{EFFECTS OF CHRONIC MORPHINE TREATMENT}

Across all three experiments, rats receiving $30 \mathrm{mg} / \mathrm{kg}$ morphine daily gained weight more slowly than rats that only received conditioning drug injections. After 2 weeks of chronic morphine treatment, there was a significant difference in percentage weight gain across the three experiments on day $15[F(2,101)=141.239, p<0.05]$. The morphine-maintained animals in Experiment 2 had an average daily weight gain of $4.92 \mathrm{~g}$. Similarly the animals in Experiment 3 gained at an average daily rate of $5.10 \mathrm{~g} /$ day. In the same amount of time, the control animals from Experiment 1 increased at a rate of $7.78 \mathrm{~g} /$ day. After 2 weeks of chronic morphine experience the animals in Experiment 3 were taken off daily morphine injections. During the following 9 days they increased in body weight at a rate of $9.93 \mathrm{~g} /$ day. While animals from Experiment 2 continued their morphine regimen for those 9 days, displaying a daily rate of weight increase of $6.30 \mathrm{~g} /$ day. The percentage increase in weight on day 24 was significantly different between groups $[F(1,60)=37.920, p<0.05]$.

When the preference for the drug-paired compartment on the initial test was compared across experiments, it was found that chronic morphine treatment significantly increased the preference for the drug-paired compartment only if the animals were being chronically treated at the time of the test $[F(2,101)=4.814$, $p>0.05]$. A CPP in animals conditioned while maintained on morphine but reactivated following withdrawal was no different than one in animals trained and tested naïve $[F(1,101)=0.087, \mathrm{NS}]$.

\section{DISCUSSION}

Propranolol and midazolam administered after reactivation, disrupted a morphine-conditioned CPP in rats that were not chronically treated with morphine. These results replicate previous demonstrations in animals not maintained on morphine that

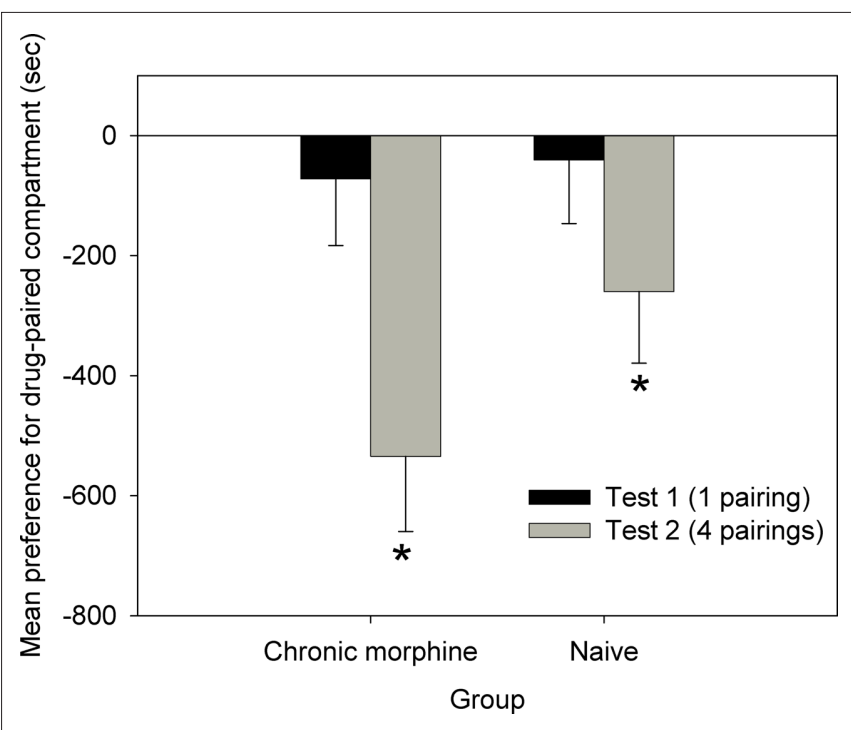

FIGURE 7 | Place conditioning with post-trial propranolol as the reinforcer, in Chronic morphine $(N=10)$, and Naive $(N=11)$ animals (Experiment 4). Data are the mean time spent in the propranolol-paired compartment minus time in the vehicle-paired compartment on Tests 1 and 2 . Error bars $=$ SEM. ${ }^{*}=p<0.05$ for propranolol- vs vehicle-paired. 
propranolol disrupts reconsolidation for a CPP induced by morphine (Robinson and Franklin, 2007b, 2010). We have previously demonstrated (Robinson and Franklin, 2007b) that such disruption of the CPP by propranolol is reactivation dependent, which is characteristic of reconsolidation block. Prior research using midazolam as a reconsolidation-blocking agent has examined only fear conditioning (Bustos et al., 2006, 2009; Zhang and Cranney, 2008), but we have now found that midazolam also blocks reconsolidation of an appetitive CPP, and that the block persists over several tests.

When animals were conditioned and reactivated while receiving daily maintenance doses of morphine, the results were strikingly different from those with naive animals. Neither midazolam nor propranolol interfered with reconsolidation, even after multiple postreactivation treatments. Instead, propranolol produced a significant increase in the preference for the compartment previously paired with morphine. This effect was not the result of peripheral beta-adrenergic blockade or the reactivation procedure since injections of nadolol, which does not readily cross the blood-brain barrier, did not increase the CPP. It is possible that higher doses might have overcome the resistance to reconsolidation but the dose of $10 \mathrm{mg} / \mathrm{kg}$ propranolol is the dose most commonly used in the literature on reconsolidation, and is 20 times greater than the dose required to block the memory enhancing effect of systemic epinephrine (Sternberg et al., 1985). Thus our results show that chronic exposure to morphine markedly alters the effect of a reconsolidation-blocking treatment, as can be seen when the effect of propranolol on reconsolidation is compared across groups with differing histories of morphine exposure.

Failure of both midazolam and propranolol to block reconsolidation in chronically treated animals cannot be attributed to concomitant morphine treatment at the time of reactivation. When animals were reactivated following 10 days of withdrawal, neither propranolol or midazolam attenuated the preference for the drugpaired compartment. Again, propranolol seemed to enhance the preference for the drug-paired compartment, though the effect occurred only after several treatments. In the controls, the CPP appeared to extinguish after five reactivations but propranololtreated animals continued to prefer the drug-paired compartment longer than their saline treated counterparts.

There is very little chance that a post-reactivation treatment would be consistently and exclusively associated with either context, nevertheless we explored (Experiment 4) whether post-trial propranolol could act as a reinforcer in rats. Explicitly pairing an exposure to one compartment with a subsequent injection of propranolol, and to the alternate compartment with an injection of saline, did not produce a preference or aversion for the compartment associated with propranolol treatment in either chronically treated or morphine-naive animals. This shows that even with a perfect association between a compartment and propranolol the motivational significance of the CPP context is not altered by a single experience of propranolol. Thus, the development of a conditioned aversion to the "morphine-paired" side cannot explain the loss of the CPP in morphine-naïve subjects (Experiment 1). Similarly, the significant increase in preference in chronically treated animals after post-reactivation propranolol cannot be explained by the development of an additional propranolol-conditioned preference for the "morphine-paired" side (Experiment 2a). After four conditioning trials with propranolol, however, an aversion to the compartment associated with propranolol was observed. Thus the fact that the $\mathrm{CPP}$ is increased on reactivation 5 in animals maintained on morphine after four repeated post-reactivation propranolol injections (Experiment 3) cannot be explained by a preference-inducing effect of propranolol. In addition, although these results do suggest that repeated propranolol injections produce what appear to be signs of aversion, it should be noted that animals with a history of chronic morphine treatment retained a morphine CPP longer than their saline treated counterparts, despite seven propranolol injections.

Comparison of the body-weight changes for the animals maintained on morphine showed the pattern typical of opioid dependence - a marked decrease in the rate of weight gain in chronically treated animals followed by a slow recovery after several days of abstinence. Chronic morphine experience also increased the size of the initial preference for the drug-paired side if the animals were maintained on morphine at the time of the test. Animals conditioned while maintained on morphine but reactivated following withdrawal were no different than animals trained and tested naïve. In contrast Harris and Aston-Jones (2003), found that chronically morphine pretreated abstinent rats showed a stronger preference for the morphine-paired environment than placebo pretreated rats. However their procedure differed from ours in several ways. They used morphine pellet implants to induce dependence, they ran two training sessions per day and they gave three drug-compartment pairings rather than four. It is possible that our subjects were more trained and have reached asymptote for the CPP, thus obscuring increased sensitivity in dependent animals.

The fact that animals trained while maintained on morphine became resistant to the reconsolidation-blocking effect of both propranolol and midazolam can possibly be explained by facilitation of conditioning by chronic morphine treatment. We have previously shown that a strongly conditioned CPP is resistant to reconsolidation block (Robinson and Franklin, 2010), and it has been shown that sensitization to morphine speeds conditioning (Mucha et al., 1982; Lu et al., 2002). We have observed that a single morphine-context pairing is sufficient to produce a reliable CPP in morphine-sensitized animals (Robinson, 2009) whereas in naïve animals conditioning requires several trials (Robinson and Franklin, 2007a). Chronic morphine exposure could be considered as extreme sensitization, and it would be expected to facilitate conditioning so that the conventional four morphine pairings would produce strong conditioning resistant to reconsolidation block. In addition, it is possible that down regulation of GABAa receptors as a result of chronic exposure to morphine (Ammon-Treiber and Hollt, 2005) contributes to the loss of the amnestic effect of midazolam. However neither of these hypotheses can explain the increase in the size of the $\mathrm{CPP}$ produced by post-reactivation propranolol in animals trained while maintained on morphine. The effect is centrally mediated since a peripheral beta-blocker did not reproduce the effect. It cannot be due to direct interaction with morphine, because propranolol was never given in conjunction with morphine, and the effect was still present in animals that had recovered from chronic morphine. Since neither propranolol nor morphine are present at the time the $\mathrm{CPP}$ is expressed the effect must be mediated by memory. It is possible that the expression of the preference in the reactivation trial could accidentally make the morphine-associated chamber become a predictor of propranolol administration but even if this could 
occur after a single pairing, it would not be expected to lead to an enhanced preference since we found that repeated conditioning to propranolol produces a place aversion, whilst a single pairing produces neither preference nor aversion (Experiment 4).

One possible explanation for our results is that the reactivation session produces extinction and that propranolol is interfering with the consolidation of this process. However several lines of evidence argue against this explanation. First of all, morphine-naïve animals treated with propranolol following reactivation (Experiment 1) lose the CPP and fail to show any signs of spontaneous recovery when re-tested 1 week later. Secondly, animals that were reactivated under chronic morphine treatment and did not receive post-trial propranolol (Experiment 2a) did not show extinction even after eight reactivation sessions. Although there is evidence in the literature that noradrenergic blockade by propranolol might disrupt extinction (Do-Monte et al., 2010; Janak and Corbit, 2011), there is no theory or experimental evidence to suggest that the disruption of extinction would enhance memory rather than maintain behavior.

The literature on the neurochemistry of dependence and withdrawal suggests mechanisms whereby post-reactivation propranolol might strengthen the associations underlying the CPP in animals chronically exposed to morphine. First, the rats chronically maintained on morphine would be in withdrawal during conditioning and CPP testing, so it is likely that the CPP is partly generated by avoidance of the saline-paired side. Propranolol has been reported to facilitate avoidance learning as measured by the number of avoidance responses and their latencies (Staneva-Stoytcheva et al., 1989). Secondly, though the literature generally maintains that norepinephrine promotes memory formation (LaLumiere et al., 2004; Liu et al., 2009), the noradrenergic modulation of memory follows an inverted-U dose-response curve. Thus the level of activity of the

\section{REFERENCES}

Aghajanian, G. K. (1978). Tolerance of locus coeruleus neurones to morphine and suppression of withdrawal response by clonidine. Nature 276, 186-188.

Akaoka, H., and Aston-Jones, G. (1991). Opiate withdrawal-induced hyperactivity of locus coeruleus neurons is substantially mediated by augmented excitatory amino acid input. J. Neurosci. 11, 3830-3839.

Ammon-Treiber, S., and Hollt, V. (2005). Morphine-induced changes of gene expression in the brain. Addict. Biol. 10, 81-89.

Baldi, E., and Bucherelli, C. (2005). The inverted "u-shaped" dose-effect relationships in learning and memory: modulation of arousal and consolidation. Nonlinearity Biol. Toxicol. Med. 3, 9-21.

Bernardi, R. E., Lattal, K. M., and Berger, S. P. (2006). Postretrieval propranolol disrupts a cocaine conditioned place preference. Neuroreport 17, 1443-1447.

Bessa, J. M., Oliveira, M., Cerqueira, J. J., Almeida, O. F., and Sousa, N. (2005). Age-related qualitative shift in emo-

noradrenergic system determines whether increasing noradrenergic activity will produce memory enhancement or amnesia (Gold and Zornetzer, 1983; Sternberg et al., 1983; Dalmaz et al., 1993; Baldi and Bucherelli, 2005). Withdrawal of morphine in dependent animals leads to adrenergic hyper-activation through increased firing of the locus ceruleus and enhanced noradrenaline release (Aghajanian, 1978; Akaoka and Aston-Jones, 1991; Fuentealba et al., 2000), and through up-regulation of the Beta-1 receptor (Kuriyama et al., 1981b; Moises and Smith, 1987). Hyperactivity of the noradrenergic system would produce a leftward shift of the inverted- $U$ dose-response curve for the effect of noradrenergic activity on memory. Since propranolol brings noradrenergic betareceptor activity back toward optimal levels it could enhance, rather than impair reconsolidation, and thus produce a larger CPP. Similar cases of enhanced reconsolidation leading to increased behavioral performance have been reported (Lee et al., 2006; Nomura and Matsuki, 2008; Tian et al., 2011).

In summary, our results suggest that prior exposure to high doses of morphine may prevent propranolol and midazolam from disrupting memory reconsolidation for environmental cues paired with morphine. Whatever the mechanism, the fact that an enhancement of the preference still occurred in detoxified animals suggests that the changes resulting from chronic morphine treatment are long lasting. It remains to be determined whether resistance to reconsolidation block produced by chronic exposure to morphine is restricted to opiates, or whether it is a limitation which extends to all drugs of abuse.

\section{ACKNOWLEDGMENT}

This research was supported by Natural Science and Engineering Research Council of Canada grant OGP6303 to Keith B. J. Franklin.

O’Brien, C. P. (1993). Cue reactivity and cue reactivity interventions in drug dependence. NIDA Res. Monogr. 137, 73-95.

Cox, V. C., and Valenstein, E. S. (1969). Effects of stimulation intensity on behavior elicited by hypothalamic stimulation. J. Comp. Physiol. Psychol. 69, 730-733.

Dalmaz, C., Introini-Collison, I. B., and McGaugh, J. L. (1993). Noradrenergic and cholinergic interactions in the amygdala and the modulation of memory storage. Behav. Brain Res. 58, 167-174.

Do-Monte, F. H., Kincheski, G. C., Pavesi, E., Sordi, R., Assreuy, J., and Carobrez, A. P. (2010). Role of beta-adrenergic receptors in the ventromedial prefrontal cortex during contextual fear extinction in rats. Neurobiol. Learn. Mem. 94, 318-328.

Eikelboom, R., and Stewart, J. (1982). Conditioning of drug-induced physiological responses. Psychol. Rev. 89, 507-528.

Ferry, B., Roozendaal, B., and McGaugh, J. L. (1999). Involvement of alpha1-adrenoceptors in the basolateral amygdala in modula- tion of memory storage. Eur. J. Pharmacol. 372, 9-16.

Frenois, F., Stinus, L., Di Blasi, F., Cador, M., and LeMoine, C. (2005). A specific limbic circuit underlies opiate withdrawal memories. J. Neurosci. 25, 1366-1374.

Fricks-Gleason, A. N., and Marshall, J. F. (2008). Post-retrieval \{beta\}adrenergic receptor blockade: effects on extinction and reconsolidation of cocaine-cue memories. Learn. Mem. 15, 643-648.

Frumkin, K. (1974). Physical dependence in rats after low morphine doses. Life Sci. 15, 455-462.

Fuentealba, J.A., Forray, M. I., and Gysling, K. (2000). Chronic morphine treatment and withdrawal increase extracellular levels of norepinephrine in the rat bed nucleus of the stria terminalis. J. Neurochem. 75, 741-748.

Gekht, A. B., Polunina, A. G., Briun, E. A., and Gusev, E. I. (2003). Neurological disturbances in heroin addicts in acute withdrawal and early post-abstinence periods. Zh. Nevropatol. Psikhiatr. Im. S S Korsakova 103, 9-15.

Gibbs, M. E., Hutchinson, D. S., and Summers, R. J. (2010). Noradrenaline 
release in the locus coeruleus modulates memory formation and consolidation; roles for alphaand beta-adrenergic receptors. Neuroscience 170, 1209-1222.

Gintzler,A. R., and Chakrabarti, S. (2006). Post-opioid receptor adaptations to chronic morphine; altered functionality and associations of signaling molecules. Life Sci. 79, 717-722.

Gold, P.E., and Zornetzer, S. F. (1983). The mnemon and its juices: neuromodulation of memory processes. Behav. Neural Biol. 38, 151-189.

Harris, G. C., and Aston-Jones, G. (2003). Enhanced morphine preference following prolonged abstinence: association with increased Fos expression in the extended amygdala. Neuropsychopharmacology 28 , 292-299.

Janak, P. H., and Corbit, L. H. (2011). Deepened extinction following compound stimulus presentation: noradrenergic modulation. Learn. Mem. 18, $1-10$.

Khavari, K.A., Peters, T.C., Baity, P. L., and Wilson, A. S. (1975). Voluntary morphine ingestion, morphine dependence, and recovery from withdrawal signs. Pharmacol. Biochem. Behav. 3, 1093-1096.

Kitchigina, V., Vankov, A., Harley, C., and Sara, S. J. (1997). Novelty-elicited, noradrenaline-dependent enhancement of excitability in the dentate gyrus. Eur. J. Neurosci. 9, 41-47.

Kobayashi, K., and Yasoshima, Y. (2001). The central noradrenaline system and memory consolidation. Neuroscientist 7, 371-376.

Kosten, T. R., and George, T.P. (2002). The neurobiology of opioid dependence: implications for treatment. Sci. Pract. Perspect. 1, 13-20.

Kreek, M. J. (2001). Drug addictions. Molecular and cellular endpoints. Ann .N. Y. Acad. Sci. 937, 27-49.

Kuriyama, K., Muramatsu, M., Aiso, M., and Ueno, E. (1981a). Alteration in beta-adrenergic receptor binding in brain, lung and heart during morphine and alcohol dependence and withdrawal. Neuropharmacology 20 , 659-666.

Kuriyama, K., Muramatsu, M., Ohkuma, S., Tamura, J., and Ping, Z. P. (1981b). Differential effects of morphine withdrawal on cerebral beta 1- and beta 2 -adrenergic receptors. J. Neurosci. Res. 6, 749-755.

LaLumiere, R. T., Nguyen, L. T., and McGaugh, J. L. (2004). Post-training intrabasolateral amygdala infusions of dopamine modulate consolidation of inhibitory avoidance memory: involvement of noradrenergic and cholinergic systems. Eur. J. Neurosci. 20, 2804-2810.
Lee, J. L., and Everitt, B. J. (2008). Reactivation-dependent amnesia for appetitive memories is determined by the contingency of stimulus presentation. Learn. Mem. 15, 390-393.

Lee, J. L., Milton, A. L., and Everitt, B. J. (2006). Reconsolidation and extinction of conditioned fear: inhibition and potentiation. J. Neurosci. 26, 10051-10056.

Liu, T.L.,Chen, D.Y., and Liang, K.C. (2009). Post-training infusion of glutamate into the bed nucleus of the stria terminalis enhanced inhibitory avoidance memory: an effect involving norepinephrine. Neurobiol. Learn. Mem. 91, 456-465.

Lu, L., Xu, N. J., Ge, X., Yue, W., Su, W. J., Pei, G., and Ma, L. (2002). Reactivation of morphine conditioned place preference by drug priming: role of environmental cues and sensitization. Psychopharmacology (Berl.) 159, 125-132.

Lukacher, G. I., Vrublevskii, A. G., and Laskova, N. B. (1987). Neurological aspects of opium addiction. $Z h$. Nevropatol. Psikhiatr. Im. S S Korsakova 87, 1653-1657.

Mogilnicka, E. (1986). Increase in betaand alpha 1-adrenoceptor binding sites in the rat brain and in the alpha 1-adrenoceptor functional sensitivity after the DSP-4-induced noradrenergic denervation. Pharmacol. Biochem. Behav. 25, 743-746.

Moises, H. C., and Smith, C. B. (1987). Changes in cortical beta-adrenergic receptor density and neuronal sensitivity to norepinephrine accompany morphine dependence and withdrawal. Brain Res. 400, 110-126.

Mucha, R. F., Kalant, H., and Linseman, M. A. (1979). Quantitative relationships among measures of morphine tolerance and physical dependence in the rat. Pharmacol. Biochem. Behav. 10, 397-405.

Mucha, R. F., van der Kooy, D., O'Shaughnessy, M., and Bucenieks, P. (1982). Drug reinforcement studied by the use of place conditioning in rat. Brain Res. 243, 91-105.

Nestler, E. J. (1993). Cellular responses to chronic treatment with drugs of abuse. Crit. Rev. Neurobiol. 7, 23-39.

Nomura, H., and Matsuki, N. (2008). Ethanol enhances reactivated fear memories. Neuropsychopharmacology. 33, 2912-2921.

Przybyslawski, J., Roullet, P., and Sara, S. J. (1999). Attenuation of emotional and nonemotional memories after their reactivation: role of beta adrenergic receptors. J. Neurosci. 19, 6623-6628.

Rattan, A. K., and Tejwani, G. A. (1997). Effect of chronic treatment with morphine, midazolam and both together on dynorphin(1-13) levels in the rat. Brain Res. 754, 239-244.
Robinson, M. J. F. (2009). Analysis of the Reconsolidation Phenomenon in a Morphine Conditioned Place Preference. Doctoral Dissertation, Montreal, QC: McGill University

Robinson, M. J., and Franklin, K. B. (2007a). Effects of anisomycin on consolidation and reconsolidation of a morphine-conditioned place preference. Behav. Brain Res. 178, 146-153.

Robinson, M. J. F., and Franklin, K. B. J. (2007b).Central but not peripheral betaadrenergic antagonismblocks reconsolidation for a morphine place preference. Behav. Brain Res. 182, 129-134.

Robinson, M. J. F., and Franklin, K. B. J. (2010). Reconsolidation of a morphine place preference: impact of the strength and age of memory on disruption by propranolol and midazolam. Behav. Brain Res. 213, 201-207.

Sadler, R., Herzig, V., and Schmidt, W. J. (2007). Repeated treatment with the NMDA antagonist MK-801 disrupts reconsolidation of memory for amphetamine-conditioned place preference. Behav. Pharmacol. 18,699-703.

Sara, S. J. (2009). The locus coeruleus and noradrenergic modulation of cognition. Nat. Rev. Neurosci. 10, 211-223.

See, R.E. (2002). Neural substrates of conditioned-cued relapse to drug-seeking behavior. Pharmacol. Biochem. Behav. 71, 517-529.

Sirvio, J., and MacDonald, E. (1999). Central alpha1-adrenoceptors: their role in the modulation of attention and memory formation. Pharmacol. Ther. 83, 49-65.

Staneva-Stoytcheva, D., Astrug, A., and Ivanov, D. (1989). Effects of some betaadrenoceptor blockers on avoidance learning in rats. Methods Find. Exp. Clin. Pharmacol. 11, 535-540.

Sternberg, D. B., Gold, P.E., and McGaugh, J. L. (1983). Memory facilitation and impairment with supraseizure electrical brain stimulation: attenuation with pretrial propranolol injections. Behav Neural Biol. 38, 261-268.

Sternberg, D. B., Isaacs, K. R., Gold, P. E., and McGaugh, J. L. (1985). Epinephrine facilitation of appetitive learning: attenuation with adrenergic receptor antagonists. Behav. Neural Biol. 44, 447-453.

Stimmel, B., and Kreek, M. J. (2000). Neurobiology of addictive behaviors and its relationship to methadone maintenance. Mt. Sinai J. Med. 67 375-380.

Stinus, L., Robert, C., Karasinski, P., and Limoge, A. (1998). Continuous quantitative monitoring of spontaneous opiate withdrawal: locomotor activity and sleep disorders. Pharmacol. Biochem. Behav. 59, 83-89.

Terwilliger, R. Z., Beitner-Johnson, D., Sevarino, K. A., Crain, S. M., and
Nestler, E. J. (1991). A general role for adaptations in G-proteins and the cyclic AMP system in mediating the chronic actions of morphine and cocaine on neuronal function. Brain Res. 548, 100-110.

Tian, S., Huang, F., Li, P., Li, Z., Zhou, S., Deng, H., and Yang, Y. (2011). Nicotine enhances contextual fear memory reconsolidation in rats. Neurosci. Lett. $487,368-371$.

Tronson, N. C., and Taylor, J. R. (2007). Molecular mechanisms of memory reconsolidation. Nat. Rev. Neurosci. 8, 262-275

Vanderschuren, L. J., De Vries, T. J., Wardeh, G., Hogenboom, F. A., and Schoffelmeer, A. N. (2001). A single exposure to morphine induces long-lasting behavioural and neurochemical sensitization in rats. Eur. J. Neurosci. 14, 1533-1538.

Vanderschuren, L. J., Tjon, G. H., Nestby, P., Mulder, A. H., Schoffelmeer, A. N., and De Vries, T. J. (1997). Morphineinduced long-term sensitization to the locomotor effects of morphine and amphetamine depends on the temporal pattern of the pretreatment regimen. Psychopharmacology (Berl.) 131, 115-122.

Volkow, N.D., Valentine, A., and Kulkarni, M. (1988). Radiological and neurological changes in the drug abuse patient: a study with MRI. J. Neuroradiol. 15, 288-293.

Zhai, H., Wu, P., Chen, S., Li, F., Liu, Y., and Lu, L. (2008). Effects of scopolamine and ketamine on reconsolidation of morphine conditioned place preference in rats. Behav. Pharmacol. 19, 211-216.

Zhang, S., and Cranney, J. (2008). The role of GABA and anxiety in the reconsolidation of conditioned fear. Behav. Neurosci. 122, 1295-1305.

Conflict of Interest Statement: The authors declare that the research was conducted in the absence of any commercial or financial relationships that could be construed as a potential conflict of interest.

Received: 15 March 2011; accepted: 08 July 2011; published online: 28 July 2011. Citation: Robinson MJF, Armson M and Franklin KBJ (2011) The effect of propranolol and midazolam on the reconsolidation of a morphine place preference in chronically treated rats. Front. Behav. Neurosci. 5:42. doi: 10.3389/fnbeh.2011.00042

Copyright $\odot 2011$ Robinson, Armson and Franklin. This is an open-access article subject to a non-exclusive license between the authors and Frontiers Media SA, which permits use, distribution and reproduction in other forums, provided the original authors and source are credited and other Frontiers conditions are complied with. 